\title{
DE PAI PARA FILHO: 0 DIREITO FUNDAMENTAL À PATERNIDADE
}

Rogério Magnus Varela Gonçalves

Doutor em direito constitucional pela Universidade de Coimbra. Mestre em direito público pela Universidade Federal da Paraíba. Professor do Centro Universitário de João Pessoa (Unipê). Advogado.

\section{Resumo}

Os direitos reprodutivos do homem têm sido esquecidos pela doutrina constitucional brasileira, eis que se tem entendido que apenas as mulheres possuem o direito de decidir acerca da continuidade ou não da gravidez. O presente estudo parte da premissa de que não existe o monopóplio ou a titularidade única das mulheres acerca da temática do surgimento de um novo ser humano, até porque se deve compreender o homem (pretenso pai) como agente de deveres, mas também de direitos, além do fato de que não se pode suprimir da figura masculina um projeto de parentalidade.

\section{Palavras-chave}

Direito fundamental à paternidade; Direitos reprodutivos; Cidadania.

\section{Abstract}

Reproductive rights of men are forgotten by the Brazilian constitutional doctrine, since the prevailing understanding is that women have the right to decide on the continuation of pregnancy. This study starts from the idea that not there is a monopoly or priority of women on the issue of the birth of a new human being, because we need to understand the man (alleged father) as an agent of duties but also rights and consider the fact not be possible eliminate the male figure of a paternity project.

\section{Key words}

Fundamental right to Fatherhood; Reproductive rights; Citizenship.

\section{Introdução}

Durante largos anos, especificamente em diversos países ocidentais, foi negligenciado o papel do pai nas escolhas atinentes ao surgimento de um novo ser humano. 
Formou-se como que uma redoma inatingível aos indivíduos do sexo masculino, porquanto caberia apenas à mulher definir se ela deveria ou não levar o seu estado gravídico adiante ou fazer a interrupção voluntária da gravidez (de forma legal, nos países em que o aborto deixou de ser criminalizado, como ocorre na Espanha fo aborto passou a ser permitido em território espanhol desde o ano de 2010. A possibilidade abortiva estava condicionada ao tempo da gestação, sendo que a regra era a permissão até a $14^{\mathrm{a}}$ semana. Em casos de grave malformação fetal, tal possibilidade era alargada até a $22^{\text {a }}$ semana. A legislação espanhola também preve que, em casos mais gravosos, o aborto possa ocorrer a qualquer momento da gravidez, desde que para tanto haja a avaliação e o aprovo de uma comissão de ética.\}, ou de forma clandestina, nos países, a exemplo do Brasil, em que o aborto ainda está posto como fato típico e antijurídico $\{\mathrm{O}$ vigente Código Penal da República Federativa do Brasil trata sobre o aborto entre os artigos 124 a 128, considerando-o como crime contra a vida humana\}).

Muitos movimentos feministas defendem a tese de que o aborto é uma questão que só diz respeito às mulheres e que, por conseguinte, não deveria ser discutida ou decidida pelos homens. Referido pensamento é uma prova do afastamento imposto aos homens. Ademais, tal ideia se mostra discriminatória e excludente, sendo passível de ser equiparada aos seguintes dizeres "o roubo é uma questão que só diz respeito aos ladróes, não devendo ser discutido por pessoas honestas" ou ainda que "a escravatura é uma questão que só diz respeito aos proprietários, não devendo ser discutida por quem não tem escravos".

Ressalte-se que existe uma lógica para o afastamento masculino da temática alusiva ao aborto. É que muitos foram os movimentos feministas que conseguiram sedimentar o entendimento de que se o útero (corpo) é da mulher, caberia apenas a ela a escolha e a decisão sobre se levaria ou não a gravidez ao final. Criou-se um movimento das mães livres. Apenas para ilustrar essas alegaçôes, é importante lembrar que Hillary Clinton, Secretária de Estado dos Estados Unidos da América, por ocasião de sua manifestação oral na Conferência da ONU para o Desenvolvimento Sustentável (Rio+20), levantou a bandeira da unicidade feminina nas questóes relativas aos direitos reprodutivos. Chegou mesmo a afirmar que devem ser assegurados os direitos reprodutivos das mulheres. Aduziu ainda que as mulheres devem dispor do direito de decidir se querem e quando querem ter filhos. Concluiu asseverando que o país por ela representado iria trabalhar para assegurar que tais direitos fossem inseridos em acordos internacionais e cumpridos pelas diversas nações.

O presente estudo, longe de buscar apequenar a importância das mulheres no processso de concepção das novas geraçóes, permite-se indagar se é correto o tratamento de menoscabo dado aos pais. Será que os homens podem ser alijados do processo de escolha acerca do surgimento dos futuros ocupantes do Planeta? Os homens devem ter apenas deveres para com os eventuais filhos que as mulheres aceitarem lhes conferir? Existe ou não 
uma afronta ao primado constitucional da dignidade da pessoa humana em relação aos homens, quando eles são relegados a um plano secundário no que tange ao tema? Existe uma só forma de enfrentar a problemática? Quando o homem aquiesce, por ato comissivo ou omissivo, ou não luta para evitar que a mulher promova a interrupção voluntária da gravidez (inibindo o seu desejo de ser pai), estar-se-á ou não diante de uma renúncia a um direito fundamental (o de ser pai)? É possível compatibilizar os interesses dos dois agentes da concepção?

Essa será a temática abordada nas linhas agora principiadas. Buscar-se-á responder aos questionamentos supracitados.

\section{Dos Direitos Reprodutivos: Monopólio das Mulheres?}

Alguns estudiosos do tema partem da premissa de que os direitos reprodutivos seriam unicamente direcionados para as mulheres. Chegam mesmo a conceituar os direitos reprodutivos como sendo "os direitos das mulheres de regular sua própria sexualidade e capacidade reprodutiva, bem como de exigir que os homens assumam responsabilidades pelas consequências do exercício de sua própria sexualidade”. (AZERÊDO; STOLCKE, 1991, p. 16). O presente estudo ousa discordar do monopólio feminino no que toca aos direitos reprodutivos. Pensar que apenas as mulheres têm tais direitos é defender que o homem nada mais é do que um mero objeto utilizado pelas mulheres para a consecução do seu direito reprodutivo próprio. Seria uma coisificação maculina, visto que ele seria reduzido a um simples auxiliar para a efetivação de um direito alheio, o de ser mãe. Seria apequenar o homem a um simples fornecedor de material biológico.

O texto faz eco das liçóes de Silva Oliveira (2012, pp. 166/167 e p. 179). para quem os direitos reprodutivos se consubstanciam num conjunto de direitos básicos relativos ao livre exercício da sexualidade e da reprodução humana. Para a autora, os direitos reprodutivos constituem verdadeiro exercício da cidadania e da dignidade da pessoa humana e se fundam nos valores preconizados pelos cânones da liberdade de planejamento familiar, intimidade privada, autodeterminação e igualdade. Portanto, propóe-se uma conceituação inclusiva acerca dos direitos reprodutivos, também englobando os homens, de sorte a eliminar o pensamento exclusivista e excludente de que apenas as mulheres seriam dotadas de ditos direitos. Ademais, a inserção masculina nessa seara prestigia o princípio da igualdade de gênero, amplamente defendida nos dias presentes.

Outro tópico deve ser levado em consideração, na medida em que questiona o monopólio feminino no que concerne aos direitos reprodutivos. Reside no fato de que, quando uma mulher promove uma interrupção voluntária da gravidez (mesmo contra o desejo ou valendo-se da ausência de informação do pretenso futuro pai), ela náo elimina apenas a carga genética proveniente de si. Ela também está a eliminar a carga genética 
proveniente do homem, ambas utilizadas para a concepção de um novo ser (com carga genética própria). ${ }^{1}$

Diante dessa evidência, é forçoso concluir que os homens têm tudo a ver com os direitos reprodutivos das mulheres com as quais se relacionam, da mesma forma que as mulheres têm total legitimidade para serem ouvidas e levadas em consideração acerca dos direitos reprodutivos dos homens com quem mantêm relacionamento sexual. ${ }^{2}$

\section{Pai: Agente de Deveres e Também de Direitos}

Os homens têm sido conclamados a assumir as suas responsabilidades em decorrência de sua paternidade. Nada mais do que correto. A questão que se coloca é que se eles devem assumir os seus deveres, parece igualmente correto que eles sejam também agentes de direitos no que tange à reprodução e na plena realização de um projeto parental pautado no princípio da paternidade responsável.

Dentre os direitos e deveres alusivos à paternidade, parece induvidosa a existência de uma premissa basilar: a conquista da condição jurídica de pai. Muitos são os homens que apenas poderão efetivar a sua paternidade mediante adoção, seja em virtude de ausência de parceiros do sexo oposto, seja em decorrência da impotência para ter cópula ou da própria impotência para gerar, especificamente nas formas radicais de azooespermia (ausência de espermatozoides) ou de necroespermia (presença de espermatozoides sem atividade) (OLIVEIRA, 2003).

Para que se concretize o desejo da paternidade e excetuando-se os casos de adoção, faz-se mister que a mulher leve a gravidez ao seu termo. Logo, na qualidade de agente de direitos e de deveres, o pretenso pai haverá de ser levado em conta para o nascimento, não sendo razoável que a mulher possa, de forma unipessoal, decidir pelo abortamento, passando ao largo do opinativo de seu companheiro de concepção.

O texto defende que se deve levar a sério a opiniáo do agente masculino da procriação nos casos de continuidade ou não da gravidez. A gravidez não é apenas da mulher, mas sim do casal. O que diferencia os gêneros é o fato de que é dentro do corpo feminino que o feto encontra hábitat adequado para o seu desenvolvimento. Mas o filho, enquanto fruto da gravidez, é dos dois, razáo pela qual não se pode afastar o homem da decisão acerca da continuidade gestacional. Noutras palavras, ele tem o direito de ser ouvido e a sua opinião não pode ser desprestigiada em se tratando de abortamento.

1 Registre-se, por respeito à dialética, que as feministas defendem que, não obstante seja carga genética alheia (do homem), teria existido uma doação quando da ejaculação. Por ser material genético doado, a mulher teria total domínio do que com ele fazer (podendo, inclusive, desprezar o que recebera), uma vez que o esperma, enquanto fluído humano, já ingressara em seu patrimônio jurídico.

2 Vai aqui uma resposta a um interessante e provocativo texto feminista: SIQUEIRA, 2000, pp. 159/168. 
A linha defendida no presente estudo coincide, em linhas gerais, com a mensagem enviada pelo presidente de Portugal à Assembleia da República, em 10 de abril de 2007, por ocasião da transformação, em lei, do Decreto no 112 /X, que regulou a exclusão da ilicitude nos casos de interrupção voluntária da gravidez em terras lusitanas. Na referida mensagem, a participação masculina restou preservada (em dimensão inferior ao que se propóe no presente estudo). Com efeito, ficou preconizado que o abortamento deveria ser precedido de um período reflexivo, com o acompanhamento de médicos, de psicólogos e de assistentes sociais. Segundo consta no citado texto, "parece ser razoável que o progenitor masculino possa estar presente na consulta obrigatória e no acompanhamento psicológico e social durante o período de reflexão" acerca da continuidade ou não da gravidez. O presidente resguardou, contudo, que tal participação masculina não teria o condão de inibir eventual decisão feminina de abortamento, eis que a ela caberia a última palavra acerca da interrupção voluntária da gravidez.

$\mathrm{O}$ trabalho aqui desenvolvido acredita que a presença masculina não haveria de ser apenas protocolar. O homem (enquanto pretenso futuro pai), como agente de direitos e de deveres, deveria ter suas opinióes apreciadas com igual dignidade e respeito aos opinativos da mulher (enquanto pretensa futura mãe).

\section{0 Direito Fundamental de ser Pai como Desdobramento do Direito à Vida}

O direito à vida, por definição e natureza está repleto de desdobramentos, densificaçôes e significados, não se limitando apenas à questão biológica. Dentre as densificações, encontra-se o direito de ter descendência, não devendo confundir-se tal assertiva com a ideia de um dever de procriação.

O indivíduo, mesmo já tendo morrido, ainda pode e deve ser considerado em sua história e memória. Outrossim, existem os que têm o desejo de, por meio dos filhos, projetar a sua existência para além do momento de sua morte. Antigamente, o exercício desse desejo haveria de ocorrer dentro da própria existência biológica. Hoje, existe a possibilidade técnica de se retardar tal concretude para data posterior ao óbito. Em virtude dos avanços da medicina e, particularmente, da biogenética, o atual estado da arte já permite a geração de um ser depois do falecimento dos progenitores biológicos. Imagine-se o caso da mulher que for inseminada com o material genético de seu falecido esposo. O filho do de cujus seria, nas liçóes de Neves Barbas (1998, pp. 129/137), como que uma herança espiritual e física, constituindo-se em elo entre o ser presente e o ser que já partiu. ${ }^{3}$

3 O presente estudo discorda do posicionamento defendido acima, porquanto náo pode ser retirada do indivíduo a sua maior essencialidade: o seu caráter individual. Ele não pode ser gerado para representar seus antepassados. Igualmente, náo pode ser culpado por atos de seus ancestrais. Embora, ao olhar para o filho, a mâe possa lembrar o pai, o filho é o filho e jamais será o pai. 
Também no sentido de defender a transmissibilidade da carga vital para as geraçóes futuras, dentro de um contexto do direito de gerar como desdobramento do direito à própria vida, Capelo de Souza (1995. pp. 203/204) aduz que a vida humana se consubstancia num "fluxo de projeção coletivo, contínuo, transmissível, comum a toda a espécie humana e presente em cada indivíduo humano, enquanto depositário, continuador e transmitente dessa energia vital".

Em linha de confirmação com a ideia em destaque, Limongi França (1994) tem entendimento de que o direito à integradidade física seria um dos aspectos fundamentais da personalidade. $\mathrm{O}$ citado autor aduz ainda que na integridade física estaria inserido o direito à vida. Este, por seu turno, compreenderia, dentre outros, o direito à concepção e à descendência; o direito ao nascimento e o direito ao planejamento familiar.

Como se observa, está-se diante da mais importante responsabilidade intergeracional: a de conceber as geraçóes futuras. Logo, o direito fundamental de ser pai é um desdobramento do direito à vida, bem como um elemento essencial para a própria continuidade da vida no Planeta.

\subsection{O Projeto Parental como Livre Desenvolvimento da Personalidade}

Além de se constituir em um desdobramento do direito à vida, é igualmente indesmentível afirmar que o projeto parental decorre do livre desenvolvimento da personalidade. Os direitos da personalidade, no olhar de Maria Helena Diniz (2008, p. 117), são dotados de uma dupla dimensão: "a axiológica, pela qual se materializam os valores fundamentais da pessoa, individual ou socialmente considerada, e a objetiva, pela qual consistem em direitos assegurados legal e constitucionalmente, vindo a restringir a atividade dos três poderes". Eles permitem que a pessoa defenda o que lhe é próprio, a exemplo da vida, da identidade, da liberdade, da imagem, da privacidade, da honra etc. em outras palavras, são direitos voltados à tutela do ser humano e que estão lastreados no primado constitucional da dignidade da pessoa humana (inciso III do art. $1^{\circ}$ da vigente Constituição Federal do Brasil).

Ingo Sarlet (2012, p. 101) defende a tese de que os direitos fundamentais são exigências e concretizaçóes do princípio da dignidade humana. Adverte que nem todos os direitos fundamentais são derivaçôes automáticas da dignidade da pessoa humana. Mesmo assim, esclarece que os direitos fundamentais constituem, por via de regra, explicitaçóes da dignidade da pessoa. ${ }^{4}$ Desta forma, a regra é que em cada direito fundamental se faz presente um conteúdo ou, pelo menos, alguma projeção da dignidade da pessoa humana.

4 Para André Ramos Tavares (2004, pp. 232 e ss.), em linha de confirmação com o pensamento nãopurista de Ingo Sarlet, não existe um elo inquebrantável entre a dignidade da pessoa humana e os direitos 
O texto ora escrito parte do entendimento de que a dignidade da pessoa humana é de difícil conceituação. Ela é mais sentida do que definida. Os direitos fundamentais teriam a missão de dar concretude à dignidade da pessoa humana, posto que estes podem ser melhor vislumbrados e avaliados pela sociedade, ao passo que a dignidade da pessoa humana permanece num plano mais abstrato. Sendo assim, e partindo-se da premissa do enquadramento do direito à paternidade como sendo um direito fundametal, é forçoso concluir pela existência de um elo inquebrantável entre os direitos fundamentais, a dignidade da pessoa humana e o direito geral de personalidade com a questão alusiva à paternidade.

O projeto de ser pai ecoa entre os direitos da personalidade. Tais direitos, sem natureza de rol taxativo, foram alvos de regulamentação própria no vigente Código Civil do Brasil, especificamente entre os artigos 11 a 21. Porém, a paternidade e a maternidade não deverão ser exercidas de forma impulsiva ou irracional. Ao contrário, no exercício desse direito, deve-se dar especial atenção ao mandamento constitucional da paternidade com responsabilidades. Com efeito, a paternidade responsável é, no Brasil, uma exigência contida no texto da própria Carta Magna ( $\$ 70$ do art. 226).

\subsection{Princípio da Isonomia entre Homens e Mulheres nas Relações Familiares}

As mulheres mantiveram e ainda mantêm uma incessante luta pela igualação substancial de direitos. As conquistas nesse campo, rigorosamente legítimas e justas, vieram acompanhadas da simetria de deveres. Tanto é assim que o inciso I do art. $5^{\circ}$ da Lei Fundamental brasileira de 1988 prescreve que homens e mulheres são iguais em direitos e obrigaçóes, nos termos da própria Constituição Federal. Ainda na órbita constitucional, e em linha de reforço da simetria, convém lembrar que o art. $226, \mathbb{\$} 5^{\circ}$, é categórico em preconizar que os direitos e deveres referentes à sociedade conjugal hão de ser exercidos igualmente pelo homem e pela mulher.

Sendo assim, qualquer tratamento assimétrico entre homens e mulheres só pode ser validado se possuir morada constitucional. Fora da Constituição todo e qualquer tratamento legislativo de desigualação de gêneros peca por inconstitucionalidade ${ }^{5}$, devendo ser combatido.

fundamentais. Nem todos os direitos fundamentais seriam desdobramentos do primado constitucional contido no inciso III do art. $1^{\circ}$ da Constituição Federal. A rigor, haveria uma consubstancialidade parcial e não total dos direitos fundamentais na dignidade da pessoa humana.

5 O texto segue a argumentação de Uadi Lammêgo Bulos (2012, p. 111), ao assinalar: "O constituinte, ao igualar homens e mulheres, acatou uma solicitaçáo há muito reclamada. Expressou em termos constitucionais as longas lutas travadas contra a discriminação do sexo feminino. Ao fazê-lo, garantiu muito mais do que a igualdade perante a lei. Assegurou a igualdade em direitos e obrigaçóes. Logo, homens e mulheres, que estiverem em situação idêntica, não poderão, seja qual for o argumento, sofrer qualquer 
O cânone em apreço foi alvo de explícito reforço por parte da norma infraconstitucional regedora da matéria. Nesse sentido, o art. 1.511 do Código Civil do Brasil pontifica que o casamento estabelece comunhão plena de vida, sendo lastreado no primado da igualdade de direitos e deveres dos cônjuges. Assim, superada a antiga regra da prevalência do pater familias, passou-se a não mais existir uma hierarquia entre os cônjuges ou entre os conviventes. Por conseguinte, não há que se falar de supremacia da vontade de um em relação ao outro. Desse modo, as opinióes do homem e da mulher, que formam um casal, devem ser tidas com igual respeito e consideração, não podendo haver mais valia automática e apriorística de um sobre o outro (MAIA JÚNIOR, 2008, p. 140).

Cabe aqui lembrar os ensinamentos de Miguel Reale (1986, p. 107) acerca do tema, quando teorizava que as questôes essenciais são decididas em comum, sendo necessária a colaboração da mulher na direção da sociedade conjugal. Para ele, em clara refutação ao contexto patriarcal que preponderou até a promulgação da Constituição Cidadã de 1988, a mulher deixou de ser simples colaboradora e companheira para passar a ter, juntamente com o seu marido ou companheiro, efetivo poder de decisão no seio da família. Ocorre que o argumento posto (o de decisões conjuntas) também serve de lastro para a inserção do homem na refutação de eventual desejo da mulher acerca da continuidade da gravidez.

\subsection{Renúncia ao Direito Fundamental da Paternidade}

Indaga-se se é possível enquadrar a situação de um homem que deseja ser pai e que se relaciona com uma mulher que não aceita ser mãe como sendo uma renúncia ao direito fundamental de paternidade.

Inicialmente, impende destacar que, durante largos anos, o tema da renúncia dos direitos jusfundamentais foi pouco enfrentado, porquanto estava sedimentado o entendimento de que ditos direitos seriam irrenunciáveis. A doutrina constitucional, ao abordar os direitos fundamentais, asseverava que eles podiam até náo ser exercidos, mas a ausência de seu exercício não seria bastante e suficiente para configurar a admissibilidade de sua renúncia (SILVA, 2012, p. 60).

Mais recentemente, parte da doutrina brasileira começou a admitir a renúncia aos direitos fundamentais, consoante se infere do opinativo de Pedro Augustin Addamy (2011, p. 58). Para ele, a renúncia a direito fundamental seria uma situação definida em lei, em que o titular do direito fundamental, expressamente, renuncia a determinadas posiçóes ou pretensóes jurídicas garantidas pelo direito fundamental. Ou, então, consente

cerceamento em suas prerrogativas e nos seus deveres, sob pena de infringir a manifestação constituinte originária. Só valem as discriminaçóes contidas na própria Constituição, e. g., a aposentadoria da mulher com menos tempo de contribuição e idade do que o homem (art. 40, $\$ 1^{\circ}$, III, a e b)". 
que o poder público restrinja ou interfira mais intensamente, por um determinado espaço de tempo e a qualquer momento revogável, tendo em vista um benefício proporcional e legítimo, direto ou indireto, pessoal ou coletivo.

Com todo o respeito ao conceito acima reproduzido, ele mais se aproxima de uma definição de restrição a direitos fundamentais do que de renúncia. Chega-se a tal conclusão em virtude da menção a um elemento normativo como limitador do direito jusfundamental. Mais adequada parece a perspectiva de renunciabilidade defendida por Jorge Reis Novais (2006, p. 235), ao afirmar:

Da própria dignidade da pessoa humana e do princípio da autonomia e de autodeterminação individual - que integram e moldam de algum modo o cerne de todos e de cada um dos direitos fundamentais - decorre o poder de o titular dispor dessa posição de vantagem, inclusivamente no sentido de a enfraquecer, quando desse enfraquecimento, e no quadro da livre conformação da sua vida, espera retirar benefícios que de outra forma não obteria. Nesse sentido, a renúncia é também uma forma de exercício do direito fundamental, dado que, por um lado, a realizaçáo de um direito fundamental inclui, em alguma medida, a possibilidade de se dispor dele, inclusive no sentido de sua limitação, desde que esta seja uma expressão genuína do direito de autodeterminação e livre desenvolvimento da personalidade individual, e porque, por outro lado, através da renúncia o indivíduo prossegue a realização de fins e interesses próprios que ele considera, no caso concreto, mais relevantes que os fins realizáveis através de um exercício positivo do direito.

Ante o exposto e partindo-se do pressuposto de que o homem opte por inibir o seu desejo paterno em prol da manutenção de seu relacionamento com a mulher (eis que ele considera mais importante para a sua vida pessoal a continuidade da união que até então mantém) que não deseja lhe dar descendência, é forçoso concluir que ele está a renunciar (ao menos momentaneamente ${ }^{6}$ ) ao seu direito fundamental de paternidade.

\subsection{Colisão de Direitos Fundamentais: Livre Disposição sobre o Próprio Corpo Versus Concretização do Direito Fundamental da Paternidade}

A questão posta em apreciação (homem que deseja ser pai e companheira que não deseja ser mãe) pode ser analisada à luz da colisão de direitos fundamentais? (GUERRA, 2007; TOMÁS DE DOMINGO, 2001) O questionamento decorre do fato de que, de um lado, existiria o direito fundamental à disposição da mulher sobre o próprio corpo

6 A transitoriedade a que alude decorre da própria dinâmica da vida, eis que o casal pode se separar, o homem pode ficar viúvo, estando livre para exercer o seu direito de paternidade com uma futura nova companheira. 
(enquanto direito de não ser mãe) (NETO, 2004, pp. 601/639) e, de outra banda, existiria o direito fundamental da concretização da paternidade (enquanto direito de ser pai). Ante essa possibilidade, parece incontornável promover uma aproximação conceitual do que vem a ser colisão de direitos fundamentais.

Não se pode perder de vista que a colisão dos direitos fundamentais é espécie do gênero colisão de direitos. As antinomias, por sua vez, são contradiçóes entre normas que ocorrem quando estas atribuem consequências divergentes para uma mesma situaçáo de fato, ou seja, quando, diante de um mesmo evento fático, existem no ordenamento comandos em sentidos opostos e que não podem ser efetivados ao mesmo tempo. Os direitos fundamentais, especificamente considerados, mesmo quando enunciados através de formulaçóes precisas, estabelecem princípios. Por conseguinte, as antinomias envolvendo normas de direito fundamental são, na verdade, colisões de princípios (PEREIRA, 2006, p. 223).

Já na visão de Roberto Barroso (2007, p. 105), a colisão dos direitos fundamentais se consubstancia em um fenômeno contemporâneo em que, salvo indicação constitucional expressa, não seria possível dirimir o conflito de forma abstrata, permanente e inteiramente dissociada das características do caso concreto. Aduz que o legislador não estaria impedido de proceder a um arbitramento, visando a solucionar o conflito. Nesse caso, pontua o doutrinador que as escolhas do legislador infraconstitucional estariam sujeitas a um duplo controle de constitucionalidade: o que se processa em tese, tendo em conta apenas os enunciados normativos envolvidos; o que se desenvolve diante do caso concreto e do resultado que a incidência da norma produz na hipótese.

O que poderia caracterizar a colisão de direitos fundamentais é o fato de se estar diante de um conflito entre normas contemporâneas e de idêntica hierarquia, com o condão de afastar dois dos clássicos critérios de superação de antinomia: o da historicidade e o da hierarquia normativa. São conflitos que emergem em concreto e são antinomais eventuais (do tipo parcial-parcial, na terminologia de Alf Ross).

Para a superação da colisão seria de bom alvitre a mobilização da técnica da ponderação dos interesses (NOVAIS, 2003, pp. 639/725). A partir dessa metodologia, uma vez constatado um conflito de interesses legítimos, deve-se buscar um melhor equilíbrio possível entre os princípios colidentes. Não seria inadequado afirmar que a ponderação pode ser caracterizada como uma técnica de decisão própria para os casos difíceis, em relação aos quais o raciocínio tradicional da subsunção não é adequado (BARCELLOS, 2006, p. 55). Registre-se, lembrando Gomes Canotilho (2003, pp. 1.236/1.237), que as ideias de ponderação (Abwägung) ou de balanceamento (balancing) surgem sempre que haja a necessidade de encontrar o direito pra resolver os casos de tensão (Ossenbühl) entre bens juridicamente protegidos.

A doutrina desenvolveu duas principais modalidades de resolução para casos em que há aparente choque entre direitos fundamentais: a concordância prática e a dimensão de 
peso ou de importância [nominada pela doutrina constitucional norte-americana (FARIAS, 1996) de posição prefencial - preferred position].

Gomes Canotilho (2003, pp. 1.186/1.187), ao estudar o primado da concordância prática, o faz em associação com o preceito da especificidade, afirmando:

As relações de complementaridade, de condicionamento e imbricação entre os princípios estruturantes explicam o sentido da especificidade e concordância prática: a especificidade (conteúdo, extensão e alcance) própria de cada princípio não exige o sacrifício unilateral de um princípio em relação aos outros, antes aponta para uma tarefa de harmonização, de forma a obter-se a máxima efectividade de todos eles.

Já a dimensão de peso ou de importância, como outro critério mobilizado para enfrentar os eventuais choques normativos (partindo-se do paradigma da ponderaçáo de interesses), parte da afirmativa de que as normas-princípios divergem das normas-regras, porquanto estas estariam pautadas na lógica do tudo (cumprimento integral) ou do nada (desrespeito total ao comando normativo). Para corroborar essa assertiva, é de bom alvitre transcrever breve passagem do pensar de Dworkin (Apud ESPÍNDOLA, 1999, p. 65), quando disse que os princípios:

[...] possuem uma dimensão que não é própria das regras jurídicas: a dimensão do peso ou importância. Assim, quando se entrecruzam vários princípios, quem há de resolver o conflito deve levar em conta o peso relativo de cada um deles (...). As regras não possuem tal dimensão. Não podemos afirmar que uma delas, no interior do sistema normativo, é mais importante do que outra, de modo que, no caso de conflito entre ambas, deve prevalecer uma em virtude de seu peso maior. Se duas regras entram em conflito, uma delas não é válida.

O ponto de interseção das duas correntes apontadas acima reside no fato de que o princípio da proporcionalidade seria utilizado como um meta-princípio, na tentativa de preservar, o mais que possível, os preceitos constitucionais em cotejo ou confronto. Seriam feitas concessôes parciais no intuito de tentar utilizar, mesmo com temperanças, os dois direitos fundamentais (que são princípios, eis que mandamentos de otimização) em colisão (STEINMETZ, 2001).

$\mathrm{Na}$ densificaçáo proposta no presente estudo e tendo em consideração o que até aqui já foi abordado, advoga-se a tese de que não existe conflito real entre direitos fundamentais, mas tão somente uma aparência de conflito, mormente tendo em conta que o indivíduo do sexo masculino pode ser pai mesmo sem a aquiescência de sua companheira (e sem que se force que ela seja mãe). ${ }^{7}$

7 Chega-se a tal conclusão, tendo em conta a seguinte lição: "Como corpo normativo harmônico e necessariamente coerente, a Constituição deve ter na interação de suas normas um referencial de coexistência 
Com efeito, a possibilidade de filiação monoparental refuta a colisão de direitos detentores de fundamentalidade. Para tanto, o homem pode se valer da adoção, bem como da maternidade de substituição (popularmente conhecida como barriga de aluguel). Ademais, agora já dentro de um contexto de biparentalidade, o homem pode findar o seu relacionamento e passar a se relacionar com outra mulher que também deseje ter filhos. Por fim, outra maneira de superação do impasse é a conclusão gestacional e a entrega da criança para o pai, sem que haja qualquer participação da agente feminina da concepção no desenvolvimento da criança. Ela estaria a renunciar ao seu direito de maternidade, sem limitar o direito do homem de ser pai.

\section{Perda de uma Chance de ser Pai}

A ausência do chamamento do pai a participar de uma decisão abortiva pode ser enquadrada como sendo a perda de uma chance de ser pai, sendo passível de indenizaçáo civil em desfavor da mulher. Proveniente do direito francês, a teoria da perda de uma chance afigura-se quando houver a subtração de uma oportunidade futura de obtenção de um benefício, bem como para que se possa evitar um dano ou prejuízo. A teoria em apreciação consagra a possibilidade de indenização de determinados danos, sendo perfeitamente aplicável na órbita das relações familiares.

O presente estudo não caminha só. Ao contrário, acompanha o pensamento de Cristiano Chaves de Farias e Nelson Rosenvald (2008. p. 81). Os citados autores advogam a tese de se enquadrar como sendo perda de uma chance a situação de aborto sem a informação ou o consentimento do outro genitor, de sorte a frustrar a concretização da paternidade.

Por outro lado, deve-se ter em conta que a perda em apreço não é definitiva. Trata-se da perda de uma chance em específico, até porque pode existir a concretização do desejo da paternidade nas seguintes hipóteses: com a mesma mulher, no futuro; o homem pode adotar uma criança; a paternidade pode advir da mãe de substituição ${ }^{8}$ ou mesmo com outra parceira sexual.

Muito mais gravosa seria a situação de errônea intervenção médica que viesse a ceifar a possibilidade reprodutiva masculina, restando ao indivíduo apenas a adoção como

pacífica, permitindo que direitos e valores aparentemente antinômicos sejam igualmente reconhecidos e prestigiados". GARCIA, 2008, p. 531.

8 Ao longo do presente estudo, serão utilizados como sinônimos os termos "mãe portadora" e "mãe de substituição", muito embora se tenha ciência de que alguns promovem a seguinte diferenciação: a mãe portadora seria aquela que recebe o óvulo já fecundado; já a mãe substituta é a que é inseminada apenas com esperma. Logo, neste caso, ela estaria também a fornecer elemento fertilizante pessoal e indispensável à concepção (óvulo a ser fecundado). Vide a respeito BARBAS, 1998, p. 145. 
forma de aceder à paternidade. A situação da transitoriedade ou da perenidade no impedimento ou na dificultação da paternidade haverá de ser levada em consideração pelo Poder Judiciário em caso de eventual procedência do pedido de indenização formulado pelo frustrado pai, mais especificamente por ocasião da fixação do dano.

Outro aspecto que náo pode ser olvidado é o fato de se estar diante de um estudo futuro de probabilidades. A perda de uma chance tem correlação com algo futuro e incerto; contudo, provável. Sendo assim, se a mãe promover, mesmo sem o consentimento e a ciência do genitor, um aborto em caso de inviabilidade fetal, parece inadequada a sua condenaçáo civil, porquanto o bem jurídico tutelado (o de ser efetivamente pai) náo poderia ser alcançado. Nos casos em que se constatar a viabilidade de vida exterior do concepto, o dano há de ser arbitrado, tendo em conta o grau de probabilidade do êxito do período gravídico e, por conseguinte, da paternidade.

\section{O Planejamento Familiar como Decisão Conjunta}

Para alguns civilistas brasileiros, a vigente Constituição Federal propiciou a defesa de um verdadeiro direito ao planejamento da filiação. Tal disposição foi alvo de densificação infraconstitucional, quando do surgimento da Lei no 9.263, de 12 de janeiro de 1996, que prevê o planejamento familiar como sendo um direito de todo cidadão. A citada norma entende a planificação da família como o conjunto de açóes de regulação da fecundidade, de sorte a garantir direitos iguais de constituição, limitaçáo ou majoraçáo da prole pela mulher, pelo homem ou pelo casal. A participaçáo governativa no planejamento familiar deve ficar adstrita a uma natureza informativa e de cunho não coercitivo, apenas no sentido de cientificação técnica aos agentes da procriação, orientando-os para "açóes preventivas e educacionais e pela garantia de acesso igualitário a informaçóes, meios, métodos e técnicas disponíveis para a regulação da fecundidade" (LÔBO, 2009, p. 197).

Da mesma forma que não se mostra minimamente aceitável que os homens possam, de forma isolada, decidir acerca do planejamento familiar, por vezes inibindo que a esposa ou companheira realize o sonho de ser mãe, parece justo e razoável que também a mulher não possa, de forma individualista, impedir que o marido ou companheiro concretize o seu direito fundamental de paternidade. A vigente Constituição da República Federativa do Brasil trata do tema no art. 226, $\$ 7^{\circ}$, ao dispor que o planejamento familiar haverá de ser pautado nos princípios da dignidade da pessoa humana e na paternidade responsável. A planificação da família deve consistir em livre decisão do casal, sendo que ao Estado apenas compete dar acesso aos recursos educacionais e científicos para o exercício do aludido direito, sendo repudiada qualquer forma coercitiva por parte de instituiçóes estatais ou particulares. 
Logo, resta indesmentível que a decisão atinente ao planejamento familiar deve ser fruto do diálogo entre homem e mulher e não de um monólogo desta última (excetuando-se em casos de família monoparental). Ademais, dentre as deliberaçóes do casal, não existe espaço, na vigente legislação brasileira (que tipifica o aborto como crime), para se escolher acerca da continuidade ou não de um estado gravídico já consolidado. Esse entendimento, fruto do respeito ao primado constitucional da legalidade, também é difundido por Pereira Júnior (2009, pp. 2.383), quando esclarece:

O casal pode planejar e replanejar sempre, adstrito a fatos novos que venham a impor retificação de projetos, como aconteceria no caso de uma eventual gravidez indesejada. Neste caso, exercer o planejamento familiar significará providenciar os meios para salvaguardar o máximo de bem - estar para a gestante e para a criança, e pensar nas providências a serem tomadas com relação à composição futura da própria família. Não entra na esfera deliberativa a possibilidade de abortar a criança, pois os pais não têm poder jurídico de tirar a vida do filho. Entraria nesse plano o uso futuro de meios temporários ou definitivos para evitar novas concepçóes.

A decisão sobre o planeamento familiar haverá de ser, a priori, do casal (excetuandose as questóes da monoparentalidade), não sendo razoável qualquer imposição masculina em face da mulher, bem como náo se admitindo o contrário. Tal decorre, dentre outros aspectos, dos primados da isonomia entre homens e mulheres, da dignidade da pessoa humana e da paternidade responsável.

\section{Conclusões}

Feitas estas ponderaçóes e com o intuito de lançar luzes que permitam responder as indagaçóes expostas na introdução do presente estudo, são esboçadas as seguintes notas conclusivas:

a) O absolutismo de se imaginar que apenas e tão somente a mulher deve decidir acerca da continuidade da gravidez, por vezes, impedindo que o homem, seu companheiro, namorado ou esposo, possa ser pai, contrasta com o pensamento de um direito dúctil. Nessa perspectiva, convém lembrar as liçôes de Gustavo Zagrebelsky (2003, pp. 14 e ss.), para quem o direito constitucional deve ser flexível e dúctil, eis que - ante a variedade de situaçóes fáticas e de pluralismos de universos culturais, éticos, religiosos e políticos - não se pode cogitar a existência de valores e princípios de caráter absoluto. Ante essa maleabilidade constitucional, não seria adequada uma resposta apriorística, pronta e acabada para todas as situaçóes. Dever-se-ia analisar o caso concreto e tomar uma decisão tópica e pontual, levando-se em conta os contornos e entornos específicos de cada relação jurídica travada entre os agentes da procriação. Nesta linha de 
raciocínio, parece que não se pode colocar no mesmo plano a decisáo de uma mulher de interromper a gravidez, tendo ela um relacionamento amoroso com um homem (seu esposo, namorado ou amante) e a decisão de outra mulher que esteja, por meio de contrato, a exercer a maternidade de substituição, de sorte a frustrar o homem (seu contratante) que pretende descendência, mas que não deseja compromisso com alguém do sexo oposto.

b) Dentre as motivaçôes legítimas tradicionais para a maternidade por substituição encontram-se a infertilidade feminina, a tentativa de impedir a transmissão de doenças genéticas e o risco de óbito para a mulher. Vera Raposo (2005, pp. 19/21) lista outras possibilidades motivacionais para a contratação de uma mãe substituta, a saber: mulher que não quer engravidar com receio de comprometer a sua carreira profissional; mulher que busca preservar a sua aparência física (especialmente naqueles casos em que a pessoa exerça uma atividade que dependa do corpo para a consecução de seu trabalho, a exemplo, de atletas de alto rendimento, atrizes e modelos); casais homossexuais e os homens que pretendam ter filhos, mas que não desejem compromisso com alguém do sexo feminino. $\mathrm{O}$ presente estudo acrescentaria mais uma hipótese de utilização de maternidade por substituição: homens que sejam heterossexuais (e fieis) e cuja mulher com quem se relaciona não tenha o desejo de ser mãe.

c) Existem duas posiçôes jurídicas favoráveis ao exitoso término da gestação: a do pai e a do nascituro. Em contrapartida, apenas seria possível a suscitação de uma posição contrária, sendo que esta seria antijurídica no direito brasileiro. Logo, o prosseguimento da gravidez seria, qualitativa e quantitativamente, superior à sua interrupção, visto que os dois interesses protegidos pelo direito devem ter primazia sobre a vontade da mãe.

d) Na hipótese de uma gestação que não seja fruto de violação sexual e tendo em conta a igual dignidade de homens (pretensos pais) e mulheres (pretensas mães), não parece razoável aceitar que a escolha sobre a gravidez caiba apenas a estas últimas. Promover o abortamento sem a ciência e consentimento do pai, ou até mesmo contra a vontade dele, é uma violência aos direitos do homem. O pai, como afirmou Pedro Pais de Vasconcelos, não é um simples aportador de esperma, de modo que sua intervenção na procriação é tão importante como a da mãe, embora a gestação seja feita no útero materno. Para o citado autor, se o futuro pai quiser se opor à interrupção da gravidez, poderá fazé-lo em nome próprio. Para tanto, poderá suscitar o direito de ser pai (que é um direito de personalidade). Ou também, na qualidade de representante legal do filho, invocar o direito que este tem de nascer. 
e) Não se aceita a imposição do opinativo da mulher no que concerne ao abortamento, tendo em conta o primado da igualdade de gêneros. A regra constitucional da simetria faz com que a ordem jurídica considere identicamente o homem e a mulher, na sua essencialidade humana. Por conseguinte, é de se repudiar a redução de qualquer deles à situação de mero objeto de outrem. Acerca do tema, o autor lusitano Pedro Pais de Vasconcelos (2009, pp. 399/400) discorda da possibilidade de se suscitar a tese da colisão de direitos fundamentais (direito de paternidade versus direito de interrupção da gravidez), sob o argumento de que inexiste um direito subjetivo do abortamento. Tal argumentaçáo nos parece mais válida para os países em que o aborto é tido como sendo fato típico e antijurídico (crime). Já nos países que legalizaram a sua prática, o citado argumento perde muito de sua força. Outro aspecto interessante do estudo aqui referido é que o autor português promove uma tipologia das situaçóes de paternidade. São sete os tipos por ele indicados, de modo que a participação paterna na decisão de interrupção voluntária da gravidez é inexistente, maior ou menor, a depender de cada uma das circunstâncias. Veja-se o elenco: a) hipótese de o pai ser desconhecido, pois, embora biologicamente exista um pai, socialmente ele não existe; b) hipótese em que a gravidez decorreu de violência sexual (estupro); c) hipótese da gravidez na adolescência; d) hipótese em que a mãe é casada ou vive more uxorio em comunhão de fato e o pai do nascituro não é o marido nem o companheiro da mãe; e) hipótese em que a mãe é casada ou vive more uxorio em comunhão de fato e o nascituro é efetivamente filho do marido ou do companheiro da mãe; f) hipótese em que a continuidade da gravidez pode levar ao óbito da máe ou gerar uma criança com severa e incurável doença, bem como com malformação congénita aguda; g) Hipótese em que a gravidez é interrompida sem que ocorra ou que seja invocada qualquer causa. $\mathrm{O}$ presente estudo, sem ter a pretensão de ser exauriente, acrescentaria outra situação já vislumbrada em hodiernos dias: o desejo abortivo fruto de arrependimento da mulher que fora contratada para exercer a função da mãe de substituição, igualmente nominada de mãe portadora (barriga de aluguel).

f) O suprimento judicial seria um mecanismo a se ter em conta nos casos em que houver a ausência de conciliação dialogada entre o homem e a mulher acerca da continuidade da gestação.

g) Na situação hipotética de a mulher se negar a ter filhos, o homem poderá se valer da mãe por substituição ou da adoção para a consecução da paternidade e da efetivaçáo do seu projeto parental. Vera Raposo (2005, pp. 47/88) traz um rol de argumentos contrários e favoráveis à maternidade de substituição. Dentre os aspectos negativos dessa prática, destacam-se: a) a instrumentalização da 
criança; b) a instrumentalização da mãe de substituição; c) a contratualização da maternidade; d) os efeitos nocivos para o casal contratante; e) os efeitos nocivos para a instituição familiar; f) a exploração da pobreza; g) alguns óbices morais à maternidade de substituição; h) a comercialização da vida humana; i) a indeterminação de maternidades e paternidades. No que concerne aos aspectos positivos sáo dignos de nota os seguintes: a) o respeito pela autonomia pessoal e contratual; b) a existência de direitos sobre o próprio corpo; c) a igualdade entre os cidadáos; d) o direito de constituir família; e) o direito à intimidade e à vida privada; f) o direito ao livre desenvolvimento pessoal; g) a efetivação das condições que permitam a realização pessoal dos membros da família; h) a dádiva da vida.

h) Muitos poderiam criticar o presente estudo dando conta de que pouco se falou das mulheres. Esta reflexão, rigorosamente justa e verdadeira, serve de paradigma para se concluir o quanto não é justo o olvidar dos homens.

\section{Referências}

ADAMY, Pedro Augustin. Renúncia a direito fundamental. São Paulo: Malheiros, 2011.

AZERÊDO, Sandra; STOLCKE, Verena (coord.). Direitos reprodutivos. São Paulo: FCC/DPE, 1991.

BARBAS, Stela Marcos de Almedida Neves. Direito ao património genético. Coimbra: Almedina, 1998.

BARCELLOS, Ana Paula de. "Alguns parâmetros normativos para a ponderação constitucional”. In: BARROSO, Luís Roberto (org.). A nova interpretação constitucional: ponderação, direitos fundamentais e relaçóes privadas. 2 ed., Rio de Janeiro: Renovar, 2006.

BARROSO, Luís Roberto. "Liberdade de expressão versus direitos da personalidade. Colisão de direitos fundamentais e critérios de ponderação". In FARIAS, Cristiano Chaves de. Leituras complementares de direito civil: o direito civil-constitucional em concreto. Salvador: Editora Jus Podivm, 2007.

BULOS, Uadi Lammêgo. Constituição federal anotada. 10 ed., São Paulo: Editora Saraiva, 2012.

CANOTILHO, J. J. Gomes. Direito constitucional e teoria da constituição. 7 ed., Coimbra: Almedina, 2003.

DINIZ, Maria Helena. Curso de direito civil brasileiro: teoria geral do direito civil. Vol. I, 25 ed., São Paulo: Saraiva, 2008. 
ESPÍNDOLA, Ruy Samuel. Conceito de princípios constitucionais. São Paulo: Editora Revista dos Tribunais, 1999.

FARIAS, Cristiano Chaves de; ROSENVALD, Nelson. Direito das famílias. Rio de Janeiro: Lumen Juris Editora, 2008.

FARIAS, Edilsom Pereira de. Colisáo de direitos: a honra, a intimidade, a vida privada e a imagem versus a liberdade de expressão e informação. Porto Alegre: Sérgio Fabris Editor, 1996.

FRANÇA, Rubens Limongi. Instituiçóes de direito civil. São Paulo: Saraiva, 1994.

GARCIA, Emerson. Conflito entre normas constitucionais: esboço de uma teoria geral. Rio de Janeiro: Lumen Juris Editora, 2008.

GUERRA, Sidney. Hermenêutica, ponderação e colisáo de direitos fundamentais. Rio de Janeiro: Lumen Juris Editora, 2007.

LÔBO, Paulo. Direito civil: famílias. 2 ed., São Paulo: Editora Saraiva, 2009.

MAIA JÚNIOR, Mairan Gonçalves. O regime da comunhão parcial de bens no casamento e na uniáo estável. Tese de doutorado policopiada. São Paulo: PUC-SP, 2008.

NETO, Luísa. $\mathbf{O}$ direito fundamental à disposiçáo sobre o próprio corpo (a relevância da vontade na configuraçáo do seu regime). Coimbra: Coimbra Editora, 2004.

NOVAIS, Jorge Reis. Direitos fundamentais: trunfos contra a maioria. Coimbra: Coimbra Editora, 2006.

. As restriçóes aos direitos fundamentais não expressamente autorizados pela Constituição. Coimbra: Coimbra Editora, 2003.

OLIVEIRA, Guilherme de. Critério jurídico da paternidade. Coimbra: Almedina, 2003.

OLIVEIRA, Maria Rita de Holanda Silva. "A família homoafetiva e a garantia da parentalidade". In: FERRAZ, Carolina Valença; LEITE, Glauber Salomão; NEWTON, Paulla Christianne da Costa (coordenadores). Cidadania plural e diversidade: a construção do princípio fundamental da igualdade nas diferenças. São Paulo: Editora Verbatim, 2012.

PEREIRA, Jane Reis Gonçalves. Interpretação constitucional e direitos fundamentais: uma contribuição ao estudo das restriçóes aos direitos fundamentais na perspectiva da teoria dos princípios. Rio de Janeiro: Renovar, 2006.

PEREIRA JÚNIOR, Antônio Jorge. “Comentário ao art. 226”. In: BONAVIDES, Paulo; MIRANDA, Jorge; AGRA, Walber de Moura (coord.). Comentários à Constituiçáo Federal de 1988. Rio de Janeiro: Editora Forense, 2009. 
RAPOSO, Vera Lúcia. De mãe para mãe: questóes legais e éticas suscitadas pela maternidade de substituição. Coimbra: Coimbra Editora, 2005.

REALE, Miguel. $\mathbf{O}$ projeto de código civil: situação atual e seus problemas fundamentais. São Paulo: Saraiva, 1986.

SARLET, Ingo Wolfgang. Dignidade da pessoa humana e direitos fundamentais na Constituição Federal de 1988. 9 ed., Porto Alegre: Livraria do Advogado Editora, 2012.

SIEGEL, Reva B. "Argumentos baseados na igualdade de gênero em prol dos direitos reprodutivos: fundamentos críticos e a evolução da expressão constitucional”. In: SARMENTO, Daniel; IKAWA, Daniela; PIOVESAN, Flávia. Igualdade, diferença e direitos humanos. Rio de Janeiro: Lumen Juris Editora, 2008.

SILVA, José Afonso da. Comentário contextual à constituição. 8 ed., São Paulo: Malheiros Editores, 2012.

SIQUEIRA, Maria Juracy Toneli. "Saúde e direitos reprodutivos: o que os homens têm a ver com isso?”. In Estudos feministas. Ano 8 (primeiro semestre), 2000.

SOUSA, Rabindranath V. A. Capelo de. O direito geral de personalidade. Coimbra: Coimbra Editora, 1995.

STEINMETZ, Wilson Antônio. Colisão de direitos fundamentais e princípio da proporcionalidade. Porto Alegre: Livraria do Advogado Editora, 2001.

TAVARES, André Ramos. "Princípio da consubstancialidade parcial dos direitos fundamentais na dignidade do homem”. In Revista Brasileira de Direito Constitucional. no 4, jul./dez. 2004.

TOMÁS DE DOMINGO. ¿Conflictos entre derechos fundamentales?. Madri: Centro de Estudios Políticos y Constitucionales. 2001.

VASCONCELOS, Pedro Pais de. "A posição jurídica do pai na interrupção voluntária da gravidez". In: CAMPOS, Diogo Leite de; CHINELLATO, Silmara Juny de Abreu (coord.). Pessoa humana e direito. Coimbra: Almedina, 2009.

ZAGREBELSKY, Gustavo. El derecho dúctil. Ley, derechos, justicia. Tradução de Marina Gascón. 5 ed., Madri: Editorial Trotta, 2003. 